\title{
Expectativas e Sentimentos em Relação à Paternidade entre Adolescentes e Adultos ${ }^{1}$
}

\author{
Daniela Centenaro Levandowski \\ Cesar A. Piccinini ${ }^{2}$ \\ Universidade Federal do Rio Grande do Sul
}

\begin{abstract}
RESUMO - O objetivo deste estudo foi examinar eventuais semelhanças e particularidades nas expectativas e sentimentos em relação à paternidade entre adolescentes e adultos que esperavam seu primeiro filho. Participaram da pesquisa 23 futuros pais (12 adolescentes e 11 adultos), que foram entrevistados em suas residências no terceiro trimestre da gestação da companheira. As respostas foram examinadas através de análise de conteúdo qualitativa, com base em quatro categorias temáticas (relacionamento com o bebê e desempenho do papel paterno, criação do filho, cuidados do bebê e mudanças pessoais). Os resultados revelaram mais semelhanças do que particularidades entre os dois grupos. Adolescentes e adultos indicaram expectativas positivas quanto ao relacionamento com o bebê e à paternidade, apesar de certa dúvida quanto a sua capacidade para exercer o papel paterno. Estes resultados sugerem que a idade não é necessariamente um fator determinante nas expectativas e sentimentos associados à transição para a paternidade.
\end{abstract}

Palavras-chave: expectativas; pais; paternidade; adolescência.

\section{Expectations and Feelings Concerning Fatherhood among Teenagers and Adults}

\begin{abstract}
The purpose of this study was to examine eventual similarities and particularities of expectations and feelings concerning fatherhood among adolescents and adults who expected their first child. Twenty-three future fathers ( 12 adolescents and 11 adults), participated in the research and they were interviewed at their homes in the third quarter of their partners' pregnancy. The answers were examined through qualitative content analysis, based on four thematic categories (relationship with the baby and performance of the father's role, child rasing, baby care and personal changes). The results revealed more similarities than particularities between the two groups. Adolescents and adults indicated positive expectations concerning relationship with the baby and fatherhood, despite some doubt as to their capacity in their role as fathers. These results suggest that age is not necessarily a determinant factor in expectations and feelings associated with the transition to fatherhood.
\end{abstract}

Key words: expectations; fathers; fatherhood; adolescence.

O estudo da paternidade tem sido relegado a uma posição de menor destaque em relação aos estudos sobre a maternidade (Levandowski, 2001a, 2001b; Levandowski \& Piccinini, 2004). Contudo, atualmente nota-se um aumento de estudos nesta área, inclusive em nosso contexto (Carvalho, 2003; Castoldi, 2002; Gomes \& Resende, 2004; Hennigen \& Guareschi, 2002; Piccinini, Silva, Gonçalves, Lopes \& Tudge, 2004; Silva, 2003), apesar de estes estudos não envolverem a questão da paternidade adolescente, área na qual há ainda uma grande escassez de pesquisas (Cabral, 2003; Costa \& cols., 2005; Fonseca, 1998). É importante que sejam desenvolvidas novas investigações sobre o tema, porque, mesmo que os pais adolescentes sejam ainda classificados como ausentes, vários vêm assumindo o seu papel,

1 O presente artigo é baseado em parte da Dissertação de Mestrado da primeira autora, intitulada "Paternidade na adolescência: Expectativas, sentimentos e a interação com o bebê", orientada pelo segundo autor, apresentada em 2001 no Programa de Pós-Graduação em Psicologia do Desenvolvimento da UFRGS. Apoio financeiro: CNPq.

2 Endereço: Instituto de Psicologia, UFRGS, Rua Ramiro Barcelos 2600/111, Porto Alegre, RS, Brasil 90035-006.E-mail: d.cl@terra. com.br. acompanhando suas namoradas em função de uma vontade pessoal e não somente por pressões familiares e/ou sociais (Cabral, 2003; Costa \& cols., 2005; Fonseca, 1998; Redmond, 1985; Siqueira, Mendes, Finkler, Guedes \& Gonçalves, 2002; Trindade \& Bruns, 1999).

No entanto, Dallas e Chen (1998) constataram certa confusão nos jovens sobre o que esperar da paternidade e do seu papel durante a gestação. Isto pode ser decorrente do fato de que, dentro de uma perspectiva de papéis sociais, gerar um filho na adolescência faz com que o jovem tenha que lidar simultaneamente com dois papéis opostos: a adolescência e a paternidade (Elster \& Hendricks, 1986; Nunes, 1998; Robinson, 1988). Ser pai confronta os jovens com a privação da liberdade, por terem que dar assistência ao recém-nascido, fazendo-os, muitas vezes, abdicar do papel adolescente (Nunes, 1998). Nos estudos realizados por Levandowski (2001b), Trindade e Menandro (2002) e Cabral (2003), a maioria dos adolescentes também mencionou como aspectos ligados ao tornar-se pai a responsabilidade e a redução da liberdade. Em particular, os jovens cariocas entrevistados por Cabral salientaram a questão de "dar exemplo" e do "ter que trabalhar", que sinalizou a diminuição do tempo livre para a "zoação" e o convívio com os pares. 
A questão da prontidão para a paternidade também tem sido investigada entre os adolescentes. Conforme revisão feita por Westney, Cole e Munford (1986), a maioria dos futuros pais não se percebe como estando pronta para o evento. Nos estudos de Allen e Doherty (1996) e Nunes (1998) foram encontrado dados que corroboram tal afirmativa, pois os participantes projetavam tornar-se pai em idade mais avançada. Também na pesquisa conduzida por Cabral (2003), com pais adolescentes cariocas, de forma geral, eles consideraram inoportuno o momento da primeira gravidez, em função da ausência de condições materiais para o cumprimento do papel de "chefe de família". Dados semelhantes foram encontrados por Aquino e cols. (2003), com pais soteropolitanos, porto-alegrenses e cariocas, pois, no momento da primeira gravidez, a ampla maioria dos jovens entrevistados $(85,6 \%$ dos homens) não estava pretendendo tornar-se pai, ou sequer pensava no assunto.

Um dos fatores que pode colaborar para a falta de prontidão psicológica dos adolescentes seria o menor conhecimento sobre o desenvolvimento infantil (Belsky \& Miller, 1986), que poderia ser limitado a algumas áreas (Parke, Power \& Fisher, 1980), sendo decorrente da menor escolaridade dos jovens ou da menor quantidade de contato e experiências com crianças (Lamb \& Elster, 1986; Marsiglio \& Cohan, 1997; Young, 1988). Outros fatores envolveriam uma expectativa irreal sobre sua habilidade para cumprir com suas obrigações paternas (Cochran, 1997) e o desejo de estabelecer autonomia, uma vez que a paternidade significaria continuar sob o controle dos pais ou da sociedade (Teti \& Lamb, 1986).

No entanto, a não prontidão para a paternidade não é fato único relatado na literatura. De acordo com Westney e cols. (1986), existem adolescentes que se consideram prontos para serem pais. No estudo de Hendricks e Montgomery (1983), eles representaram $40 \%$ dos jovens entrevistados. Além disso, aproximadamente $60 \%$ indicaram que a experiência da paternidade mudaria sua vida de forma positiva. Também os jovens entrevistados por Cabral (2003), apesar de considerarem que a gravidez havia ocorrido em um momento inoportuno, fizeram referência ao fato de não estarem arrependidos por isso, considerando-a um evento positivo em suas vidas.

Ainda no estudo de Allen e Doherty (1996), os pais adolescentes mencionaram o significado positivo da paternidade, vendo o filho como uma dádiva divina. Muitos deles indicaram que ser pai contribuiu para seu desenvolvimento pessoal, mostrando um entendimento profundo desta experiência, estando conscientes dos desafios e dos problemas associados a ela. Também no estudo de Dellmann-Jenkins, Sattler e Richardson (1993), para a grande maioria dos adolescentes os estresses da parentalidade estavam sendo bem enfrentados. Eles referiram sentirem-se seguros e confiantes em seu papel parental. Por fim a interação livre pai-bebê entre pais adolescentes e adultos, aos três meses de vida do bebê, não apresentou diferenças significativas em termos dos comportamentos paternos em relação à criança (Levandowski, 2001b; Levandowski \& Piccinini, 2002).

Com respeito à família de origem destes pais, a literatura aponta um padrão de relação familiar característico, de relação bastante próxima com a própria mãe, enquanto o pai seria emocional e/ou fisicamente ausente (Allen \& Doherty, 1996; Dallas \& Chen, 1998; Elster \& Hendricks, 1986;
Trindade \& Bruns, 1999). Esta situação poderia influenciar negativamente o adolescente, por receber uma mensagem de que em seu futuro papel não necessitaria se envolver com o bebê, por ser esta uma tarefa feminina (Teti \& Lamb, 1986). Para Trindade e Bruns (1999), a presença de um modelo de atuação paterna auxilia o rapaz na sua vivência como pai, possibilitando-lhe um parâmetro de como agir. O pai pode ser utilizado como modelo direto, o que gera um repetir de suas ações; ou indireto, no momento em que o adolescente reflete sobre sua experiência e a recria, elaborando uma maneira própria de educar seu filho e se relacionar com ele.

De fato, Allen e Doherty (1996) e Trindade e Bruns (1999) encontraram como modelo paterno de adolescentes o seu próprio pai. No entanto, alguns participantes referiram que estavam sendo melhores para suas crianças do que seus pais haviam sido para eles (Allen \& Doherty, 1996). Os jovens caracterizaram o seu papel como de provedor econômico e de suporte emocional para a família, o que também apareceu nos estudos conduzidos por Trindade e Menandro (2002). De acordo com Allen e Doherty (1996), estes pais também viam a si mesmos como os principais disciplinadores de suas crianças, talvez como um desejo de contrabalançar a indulgência materna ou pelo ressentimento em função da ausência paterna.

Dallas e Chen (1998) constataram que os participantes de seu estudo consideravam como competências da paternidade, tarefas como o cuidado da criança (afeto, direção e disciplina, alimentação, troca de roupa, ida ao médico) e o apoio financeiro e com as tarefas domésticas. Cabe salientar que a questão do apoio financeiro foi predominante nos estudos conduzidos por Siqueira e cols. (2002) e Cabral (2003) no contexto brasileiro. Nesse sentido, percebe-se que os pais adolescentes enfrentam muitas questões semelhantes às de pais adultos, apesar de terem menos recursos que eles.

No que diz respeito ao cuidado do bebê, muitas vezes os adolescentes desejam auxiliar financeiramente e participar (Robinson, 1988). Nesse sentido, conforme Christmon (1990), a auto-imagem do adolescente teria uma influência importante no seu desejo de envolvimento com o bebê, bem como as expectativas pessoais em relação ao papel paterno. Embora, por um lado, alguns adolescentes acreditem que podem influenciar positivamente a vida de sua criança, pela manutenção de contato e envolvimento (Dallas \& Chen, 1998), por outro, eles podem vivenciar vários problemas que, em muitos casos, podem diminuir a intensidade de suas aspirações (Rhein \& cols., 1997), tais como: o aumento da responsabilidade (Allen \& Doherty, 1996), a educação da criança (Dellmann-Jenkins \& cols., 1993), a falta de recursos financeiros (Cabral, 2003; Dallas \& Chen, 1998; Heilborn \& cols., 2002; Hendricks, 1980; 1988), o sentimento de falta de maturidade e de frustração por tentarem conciliar o cuidado da criança e a vivência da adolescência (Dallas \& Chen, 1998), a perda da liberdade, os conflitos com a mãe do bebê e com vários membros da família da parceira, bem como a dificuldade de freqüentar a escola (Hendricks, 1980; 1988).

Desta forma, o objetivo deste estudo foi examinar as semelhanças e particularidades nas expectativas e sentimentos em relação à paternidade entre adolescentes e adultos que esperavam seu primeiro filho. Esperava-se, com este estudo, 
Tabela 1. Caracterização dos participantes.

\begin{tabular}{|c|c|c|c|c|c|}
\hline $\mathbf{N}^{\circ}$ & Idade & Estado civil & $\begin{array}{c}\text { Escolaridade } \\
\text { em anos }\end{array}$ & Ocupação & Sexo do bebê \\
\hline \multicolumn{6}{|c|}{ Futuros pais adolescentes } \\
\hline 1 & 18 & Solteiro & 9 & Operador de xerox & Masculino \\
\hline 2 & 19 & Companheiro & 8 & Marceneiro & Masculino \\
\hline 3 & 18 & Companheiro & 5 & Consertos eletrônicos & Feminino \\
\hline 4 & 16 & Companheiro & 7 & Fabricação de coleiras & Feminino \\
\hline 5 & 19 & Casado & 11 & Auxiliar de escritório & Masculino \\
\hline 6 & 18 & Companheiro & 7 & Auxiliar de escritório & Masculino \\
\hline 7 & 17 & Solteiro & 9 & Office-boy & Feminino \\
\hline 8 & 18 & Companheiro & 10 & Auxiliar de escritório & Masculino \\
\hline 9 & 18 & Companheiro & 5 & Pedreiro/Estudante & Masculino \\
\hline 10 & 19 & Companheiro & 11 & Supridor & Masculino \\
\hline 11 & 17 & Solteiro & 10 & Estudante & Feminino \\
\hline 12 & 16 & Companheiro & 4 & Estudante & Masculino \\
\hline \multicolumn{6}{|c|}{ Futuros pais adultos } \\
\hline 13 & 27 & Casado & 5 & Pedreiro & Feminino \\
\hline 14 & 30 & Casado & 5 & Zelador de igreja & Masculino \\
\hline 15 & 34 & Casado & 10 & Auxiliar de escritório & Feminino \\
\hline 16 & 30 & Casado & 11 & Marceneiro & Feminino \\
\hline 17 & 28 & Casado & 11 & Almoxarife & Feminino \\
\hline 18 & 38 & Casado & 6 & Mecânico & Feminino \\
\hline 19 & 25 & Companheiro & 11 & Representante vendas & Masculino \\
\hline 20 & 25 & Casado & 13 & Comerciante & Feminino \\
\hline 21 & 32 & Casado & 14 & Servidor público federal & Masculino \\
\hline 22 & 29 & Casado & 11 & Representante vendas & Masculino \\
\hline 23 & 31 & Companheiro & 6 & Comerciante & Masculino \\
\hline
\end{tabular}

atender à demanda de conhecimento sobre a realidade de pais adolescentes e à falta de estudos comparativos entre adolescentes e adultos.

\section{Método}

\section{Participantes}

Participaram deste estudo 23 futuros pais, 12 adolescentes e 11 adultos. Todos esperavam seu primeiro filho e suas companheiras não apresentaram complicações físicas durante a gravidez. Todos faziam parte do Estudo Longitudinal de Porto Alegre: Da Gestação à Escola (Piccinini, Tudge, Lopes \& Sperb, 1998), que acompanha 89 casais desde a gestação até os anos escolares, envolvendo pais e mães com diferentes idades, níveis sócio-econômicos e configurações familiares ${ }^{3}$. Para fins do presente estudo selecionaram-se todos os futuros pais adolescentes disponíveis e buscou-se emparelhá-los com pais adultos, em termos de morarem ou não junto com

3 Esta pesquisa recebeu aprovação do Comitê de Ética do Hospital de Clínicas de Porto Alegre (Processo n 98293 , de 30 de outubro de 1998). a companheira, bem como quanto à escolaridade e nível sócio-econômico.

Os pais foram selecionados em dois hospitais da rede pública da cidade de Porto Alegre que realizavam grupos de gestantes (18), por indicação (02) e através de anúncio em veículos de comunicação locais (03). A seleção se deu através de suas companheiras, que preencheram uma Entrevista de contato inicial contendo alguns dados demográficos dos membros do casal. Aqueles que se enquadravam nos critérios do estudo (ex: estar esperando o primeiro filho, no terceiro trimestre da gestação e sem complicações físicas) foram contatados posteriormente por telefone. A recusa dos futuros pais em participar do estudo foi baixa, cerca de $20 \%$ entre todos os contatados.

A Tabela 1 apresenta as características demográficas dos participantes. No grupo adolescente, a idade variou de 16 a 19 anos $(M=17,7$ anos, $D P=1,0)$, e no grupo adulto, de 25 a 38 anos $(M=29,9$ anos, $D P=3,8)$. A escolaridade variou, no grupo adolescente, de quatro a 11 anos $(M=7,9$ anos, $D P=2,3)$ e no grupo adulto, de cinco a 14 anos $(M=9,2$ anos, $D P=3,3)$. O nível sócio-econômico variou de baixo a médio, com base na escolaridade e profissão dos futuros pais. Em geral os participantes exerciam alguma atividade remunerada. 


\section{Delineamento e procedimentos}

Foi utilizado um delineamento de grupos contrastantes (Nachmias \& Nachmias, 1996), sendo um de futuros pais adolescentes e outro de futuros pais adultos. Foram examinados, em cada grupo, as expectativas e os sentimentos dos futuros pais em relação à paternidade.

Os pesquisadores compareceram a seis grupos de gestante para explicar às mesmas os objetivos da pesquisa e os procedimentos que seriam realizados. Aquelas que desejavam participar preenchiam uma Entrevista de contato inicial, que era usada para verificar os casais que atendiam aos critérios de seleção dos participantes, descritos acima. Após isso, era feito um contato telefônico para marcar a entrevista, realizada na residência do casal no terceiro trimestre da gestação, entre o sétimo e o oitavo mês. Neste dia, ambos assinavam inicialmente um Termo de consentimento informado (GIDEP, 1998a), e, num segundo momento, eram solicitados a preencher a Entrevista de dados demográficos do casal, com o objetivo de confirmar e complementar os seus dados demográficos.

Em um terceiro momento, era realizada individualmente com o futuro pai a Entrevista sobre a gestação e as expectativas do futuro pai, que tinha duração de aproximadamente 60 min e era gravada, sendo posteriormente transcrita. Outros instrumentos de avaliação da maternidade, do casal e da interação familiar foram também aplicados, conforme descritos em Piccinini e cols. (1998), mas não foram objetos de análise para o presente estudo. ${ }^{4}$

\section{Instrumentos}

Entrevista de contato inicial (GIDEP, 1998b): foi preenchida pelas gestantes nos hospitais com o auxílio da pesquisadora, ou por telefone, com o objetivo de selecionar os possíveis participantes do estudo. Investigava alguns dados demográficos básicos para a seleção da amostra, tais como idade da gestante e do companheiro, escolaridade, profissão, estado civil, existência de outros filhos, estado de saúde durante a gestação e data prevista para o nascimento do bebê. Era também anotado o telefone e/ou endereço para o contato posterior.

Entrevista de dados demográficos do casal (GIDEP, 1998c): visava à obtenção de dados demográficos adicionais sobre os membros do casal, tais como moradores da casa, tempo de trabalho, etnia e religião.

Entrevista sobre a gestação e as expectativas do futuro pai (GIDEP, 1998d): investigava diversos temas, como sentimentos durante a gestação da companheira, envolvimento com a gestação, mudanças pessoais e conjugais percebidas, além de expectativas em relação ao bebê, ao desempenho do papel paterno, ao desempenho da companheira como mãe, etc. As questões da entrevista que embasaram em particular o presente estudo foram: "Como tu imaginas o teu relacionamento com o bebê quando ele/a nascer?”; "Como tu te imaginas como pai?"; "O que tu te imaginas fazendo com o

4 No estudo de Levandowski e Piccinini (2002), os autores analisaram a interação livre pai-bebê aos 3 meses de vida do bebê, utilizando a mesma amostra do presente estudo. bebê?"; "Como tu te imaginas atendendo o bebê (alimentando, consolando, fazendo dormir, brincando)?”; “E quando ele não quiser dormir ou comer, ou quando chorar?”; "Em que tu achas que vais poder ajudar a tua companheira nos cuidados do bebê??”; "O quanto tu achas que o bebê irá mudar a tua vida e a da tua companheira?"; "Em que aspectos tu pensas que ocorrerão mudanças?"; "Como tu achas que vai te sentir com estas mudanças?”; "Como tu imaginas que vais criar o/a teu/tua filho/a?".

Quando os temas destas questões apareceram em resposta a outras questões da entrevista, eles também foram considerados para fins de análise.

\section{Resultados e Discussão}

As respostas dos futuros pais foram examinadas através de análise de conteúdo qualitativa (Bardin, 1977; Laville \& Dionne, 1999). A análise ocorreu de acordo com o esquema a seguir: 1) transcrição de todas as entrevistas; 2) demarcação de unidades temáticas; 3) criação de uma estrutura de categorias temáticas ampla, a partir da leitura das entrevistas e de outras estruturas de análise utilizadas previamente (Krob, 1999; Martini, 1999); 4) identificação das unidades temáticas em cada entrevista; 5) análise propriamente dita. Dois codificadores foram utilizados para a identificação das categorias e análise das entrevistas. Eventuais discordâncias na codificação eram dirimidas através de discussão e, quando necessário, contou-se com a apreciação de um juiz.

Para fins de análise, foram consideradas quatro categorias temáticas envolvendo as expectativas e sentimentos paternos, denominadas: 1) Relacionamento com o bebê e desempenho do papel paterno; 2) Criação do filho; 3) Cuidados do bebê e 4) Mudanças pessoais. Cada uma destas categorias será exemplificada com relatos dos futuros pais e discutida a seguir, com base na literatura. Durante o procedimento de análise, buscou-se destacar inicialmente as semelhanças dos relatos dos futuros pais adolescentes e adultos para cada categoria considerada. Num segundo momento, foram destacadas as eventuais particularidades entre os dois grupos.

\section{Relacionamento com o bebê e desempenho do papel paterno}

Nesta categoria foram incluídos os relatos dos pais a respeito de suas expectativas e sentimentos quanto ao relacionamento com o seu filho e quanto ao seu desempenho como pai. Entre as subcategorias consideradas, destacamse: não se imaginar como pai, imaginar-se como um pai presente e participativo, imaginar um bom relacionamento com o filho, imaginar dificuldades no relacionamento com o filho, ter preocupações e dúvidas quanto ao desempenho do papel paterno e evitar repetir os erros dos próprios pais na criação do filho.

Alguns dos futuros pais (J1, J3, J4, J8, A13, A15, A18, A20, A23) referiram não saber como seria seu relacionamento com o bebê, não tendo ainda se imaginado no papel de pai: “A gente não tem idéia sem estar com ele junto, tu não tens [idéia de] como vai ser." (A18) ${ }^{5}$. Dois participantes (J8, A18), embora enfatizando não saber o que aconteceria, acabaram descrevendo algumas expectativas e sentimentos: "Ah, eu não 
sei como é que vai ser. Eu imagino que eu vou estar.. pelo menos no primeiro mês, dois meses, em cima dele, babando, idealizando. E vou tentar me dedicar ao máximo, por causa que ela já vai estar, [ele] já vai sair de dentro dela, e ela já vai estar amamentando, ele já vai conhecer ela. E eu vou tentar que ele me conheça como pai e não como as outras pessoas normais, entendeu. Como alguém diferente" (J8).

Alguns dos futuros pais imaginavam-se como pais bastante presentes (J1, J9, J5, J10, J11, A14, A16, A18, A21, A22, A23), "corujas" e apegados ao filho (J1, J5, J7, J8, A22), carinhosos e atenciosos (J6, J7, J8, J9, J10, A16, A19, A21), interessados (J7, J8), brincalhões (J4, J9), amigos (A22, A23), enfim, bons pais (J4, J6, J9, A14, A19, A20) e até mesmo superpais (J6, A19, A21, A22). Como conseqüência, pensavam que teriam um bom relacionamento com seu filho (J10, J12, A21), educando-o (J10, J11, A23), dando limites (J10, J12, A16, A17, A20, A21, A23) e servindo de exemplo (J5, A22).

Alguns também desejavam ensinar para o filho o que aprenderam com os próprios pais (J6, J10, J11, A14, A16, A20, A22), mas corrigindo seus erros (J3, J7, J11, A17): "Pretendo dar o máximo de tudo para ele (...) eu quero dar de tudo: carinho, atenção, bastante atenção e carinho. E ser um super pai para ele, espero, que graças a Deus estou com ele (...) Eu pretendo ser um bom pai, dando ao meu filho o que eu tive, e o que eu não tive também pretendo dar" (J6); "Bah, vou ser um paizão bem legal, bem carinhoso, e como eu disse para ti, eu gosto muito de criança, então vai ser o xodó da casa, vai ser bem legal mesmo. Olha, tudo que tiver de bom eu vou dar para ele, o que tiver ao meu alcance, mas dar o melhor para ele, não vai faltar nada“ (A19).

Os futuros pais também esperavam encontrar algumas dificuldades no futuro relacionamento com o bebê, sem, contudo, especificá-las. Apareceu ainda uma preocupação, uma dúvida quanto a acertar ou não como pai (J11, A20) e a responsabilidade desta nova função (J3, A18): “Eu não sei te dizer como é que eu vejo o relacionamento, não sei, eu vou procurar ser um bom pai, mas não sei se vou acertar, também não sei se ela [a companheira] vai [acertar]” (A20); “Ah, eu não imagino como que vai ser assim (...) Ah, é uma responsabilidade grande, mas tem as suas recompensas” (J3).

Tomando-se conjuntamente as falas dos participantes quanto à primeira categoria examinada, constata-se que tanto adolescentes quanto adultos esperavam ter um bom relacionamento futuro com seu filho, desempenhando com sucesso o novo papel paterno, até mesmo como uma tentativa de superar o próprio pai. Resultados semelhantes foram encontrados por Westney e cols. (1986) entre adolescentes e por Anderson (1996) entre adultos. O desejo dos participantes de "fazer a coisa certa" é também mencionado na literatura (Brazelton \& Cramer, 1992; Daly, 1993). Aliás, o fato de tentar ser como o próprio pai mais uma vez corroboraria os achados de outros estudos na área de apego e família, de que os genitores servem como modelo parental direto ou indireto para os futuros pais e mães (Brazelton \& Cramer, 1992; Parke, 1996; Szejer \& Stewart, 1997; Trindade \& Bruns, 1999).

5 O número identifica o participante, conforme relacionado na Tabela 1, enquanto a letra indica se era um pai adulto (A) ou adolescente (J).
Entretanto, chama atenção o fato de que, nos dois grupos, aparece uma certa dúvida dos participantes quanto à sua capacidade para desempenhar o papel paterno, e uma certa dificuldade para imaginar-se como pai. Tal achado, em relação aos adolescentes, confirma as idéias trazidas por Cochran (1997), para quem alguns jovens possuem uma expectativa irreal sobre sua habilidade para cumprir com as obrigações paternas. Em relação aos pais adultos, concorda com os achados de Piccinini e cols. (2004), acerca das preocupações dos pais quanto à sua inexperiência em relação aos cuidados do bebê. Além disso, esta dúvida, de acordo com Szejer e Stewart (1997), faz parte do processo de transição para a paternidade.

Mas, mesmo descrevendo-se no futuro relacionamento, os participantes passam uma impressão de ainda estarem um pouco distantes em relação a este papel. Talvez isso também seja decorrência da vivência indireta da gravidez pelo homem (Parke, 1996; Sherwen, 1986; Szejer \& Stewart, 1997). Ao mesmo tempo, poderia ser decorrente de uma falta de modelos paternos e da revolução social atual em relação ao que seriam as funções e comportamentos ideais a serem seguidos pelos pais, documentados pela literatura (Daly, 1993; Gomes \& Resende, 2004; Parke, 1996; Piccinini \& cols., 2004). Assim, mais do que nunca, os futuros pais sentem-se perdidos e confusos quanto ao que esperar do novo papel, pois este se encontra em um processo de redefinição: de um lado, existem as demandas do papel tradicional de pai (provedor da família) e, de outro, novas demandas de maior participação e envolvimento (Bustamante, 2005; Carvalho, 2003; Castoldi, 2002; Costa, 2002; Costa \& cols., 2005; Gomes \& Resende, 2004; Trindade, 1993).

Finalmente, comparando-se os dois grupos, percebe-se que, para alguns jovens, a expectativa quanto ao desempenho do papel paterno apareceu bastante idealizada, no caso, ser um "superpai", de certa forma ignorando ou negando as dificuldades que poderão surgir no decorrer do tempo, o que não aconteceu entre os adultos. Contudo, estes resultados não corroboram os do estudo de Allen e Doherty (1996), que revelaram que adolescentes norte-americanos tinham consciência das dificuldades relativas ao desempenho do papel paterno. É possível que diferenças metodológicas e de seleção dos participantes expliquem, pelo menos parcialmente, estas diferenças.

\section{Criação do filho}

Esta categoria englobou temas relativos à forma como os pais imaginavam criar seus filhos. Foram identificadas como subcategorias: aconselhar e orientar o filho, dar liberdade para o filho fazer suas próprias escolhas, criar o filho da mesma forma como seus pais o fizeram, não aceitar questionamento do filho em relação à sua forma de criá-lo, não saber como criar, pela necessidade de conhecer o filho primeiro para saber como melhor agir com ele.

Vários futuros pais se imaginavam aconselhando o filho (J7, J11, A14, A17, A19, A20), mostrando a ele o que é certo e errado (J6, J9, A17, A19, A20, A22), mas, ao mesmo tempo, dando liberdade para que fizesse suas próprias escolhas (J3, J7, J11, A19, A22): “Dando bastante conselho. É que muitas vezes a gente é criado, eu mesmo fui criado de um 
jeito que não era para mim ser criado. A minha mãe quis me mimar, mas eu botei a cara na vida e vi que a vida não é como ela quis mostrar para mim, e eu não quero que a J. tenha a mesma ilusão, de estar sempre lá embaixo da saia da mãe, essas coisas assim. (...) Não [quero] opinar muito, opinar tudo bem, mas não decidir, tipo na hora de pensar em uma faculdade, coisa assim" (J7); "Procurar criar ela dentro da realidade dela (...). Se der para ter, tem, se não der, espera que um dia vai ter, enxergar a realidade do mundo. (...) A nossa linha vai ser essa aí, não vamos ser nenhum, dois militares dentro de casa, ditando regras e coisa, mas ditando o que é certo e errado, o resto quem vai ter que descobrir é ela” (A17).

Alguns futuros pais também mencionaram um desejo de criar o filho como haviam sido criados pelos próprios pais $(\mathrm{J} 4$, J6, A19, A20): “Eu pretendo passar para ele o que o meu pai me passou, que nesse mundo tem muitas coisas ruins e tem as coisas boas também. Vou passar as coisas boas para ele, e depois mostrar aos poucos as coisas ruins, coisas que ele não deve fazer, que aí vai pela cabeça dele" (J6); "Eu me imagino como o meu pai. Um cara (...) que é duro quando precisa, acho que vou ser assim, pelo exemplo que eu tive. Eu acho importante saber dar uma linha, não empurrar, dizer 'Eu quero que tu vás por aqui', mas dizer 'O caminho certo é por ali, procura ir por ali,", (A20).

Um futuro pai (A23) referiu ainda criar o filho sem aceitar seus questionamentos. "Eu penso que como a gente, a gente forma, eu jamais vou perguntar para ele o que ele acha. Como a gente está criando ele, o que a gente determinar eu acho que ele tem que aceitar que é aquilo, pelo menos até ele começar... quando ele se soltar sozinho. Isto eu digo até a adolescência. Não vou admitir que ele ponha o que a gente falar em dúvida, isso eu vou deixar bem claro, pelo menos no início, depois sim, se ele tiver outras idéias, a gente dá mais margem para isso".

No entanto, dois futuros pais relataram não saber como criariam seu filho (J1, J5), e outro mencionou que seria necessário primeiro conhecer a criança, para depois saber como agir com ela (A13): “Ah, nem sei, só vendo na hora mesmo. A pessoa para poder educar, eu acho que primeiro ela tem que começar a conhecer bem aquela criança, para saber quais os pontos mais difíceis dela".

De modo global, as falas dos futuros pais refletiram uma expectativa de criarem seus filhos em uma relação amigável, baseada no aconselhamento, principalmente informando sobre o certo e o errado, embora deixando liberdade para o filho escolher seu caminho. Nesse sentido, aparece um modelo ideal de relacionamento pai-filho. Segundo Gomes e Resende (2004), isto poderia estar ocorrendo para compensar a falta de afeto na relação com os próprios pais, esperando para si uma paternidade ligada ao afeto e ao diálogo.

Entre os grupos, a partir de uma comparação dos relatos, notou-se que os adolescentes mencionaram mais a questão da liberdade e tiveram uma idéia menos clara sobre como criar seu filho do que os adultos, que enfatizaram mais a questão do aconselhamento, sugerindo maior diretividade do papel paterno. Estes achados podem estar relacionados ao momento de vida dos jovens, em que a liberdade é bastante valorizada como caminho para a autonomia em relação aos próprios pais. Ainda não parece haver entre eles uma identificação com o papel paterno como aquele que limita, que educa, talvez por ser disso justamente que desejam fugir neste momento de suas vidas. Além disso, a idéia menos clara dos adolescentes sobre como criar o filho poderia ser decorrente do menor conhecimento sobre o desenvolvimento infantil (Belsky \& Miller, 1986), em função da menor quantidade de contato e experiências com crianças (Lamb \& Elster, 1986; Marsiglio \& Cohan, 1997; Young, 1988).

Aparece novamente, nos relatos dos participantes, um desejo de repetição do modelo paterno, especialmente os aspectos positivos, o que corrobora a literatura consultada (p. ex., Trindade \& Bruns, 1999).

\section{Cuidados do bebê}

Nesta categoria foram incluídas as falas dos participantes que se referiam à sua participação nos cuidados do bebê. Como subcategorias temáticas destacaram-se: desejo de ajudar no cuidado do filho, experiência no cuidado de crianças, desconhecimento e vontade de aprender a cuidar de crianças, desejo de ajudar em tudo, ajuda em tarefas específicas, uso de recursos próprios para atender o bebê em momentos de dificuldade, busca de recursos externos para atender o bebê em momentos de dificuldade e dúvidas quanto à capacidade pessoal para atender a criança.

Muitos futuros pais relataram um desejo de ajudar no cuidado do bebê (J4, J5, J6, J7, J10, J11, J12, A13, A14, A15, A16, A17, A21, A22), até por já terem experiência com isso, por cuidarem de seus irmãos, primos ou afilhados $(\mathrm{J} 2$, J4, J9, J10, J11, J12, A13, A15, A16, A17, A18, A19, A21). Contudo, alguns pensaram que cuidar do próprio filho seria diferente (J4, J9, J10), apesar de não se imaginarem com dificuldade para isso (A18, A19): "Vou sair, vou dar banho. [Vou estar sempre] ao redor dele, brincando com ele, dando atenção. (...) Eu já tenho prática, eu cuidava as minhas irmãs, cuidava até o filho da irmã dela. Cuidava ele quando ele nasceu, eu sei de tudo. Agora vai ser diferente, agora vai ser o meu filho" (J9); “Olha, eu tive uma experiência muito grande, porque quando eu tinha uns 15 anos a minha irmãzinha nasceu. Então eu que cuidei da minha irmã (...) eu ficava só em casa, não trabalhava, só estudava, então eu cuidei, dava banhinho, trocava fralda e fazia dormir, pegava no colo, quanto a isso eu não me preocupo, porque eu já tenho uma grande experiência da minha irmãzinha, das minhas primas que tiveram filho bem antes também. Então para mim não tem mistério, não me apavoro com isso, sei que eu vou agir bem natural com isso, com certeza" (A19).

No entanto, dentre os que não possuíam conhecimento sobre o cuidado infantil, alguns referiram um desejo de tentar aprender e se esforçar para acertar (J2, J6, J10, A13, A16, A20, A23): “Ah, eu pretendo saber ajudar, qualquer coisa que eu puder eu ajudo, se eu não puder também, tento, se eu errar, eu faço de novo" (J12).

Quando questionados sobre o que poderiam fazer para ajudar a companheira nos cuidados com o bebê, os futuros pais responderam de forma vaga, dizendo que ajudariam em tudo que pudessem (J1, J3, J5, J10, J11, J12, A14, A20), em quase tudo (J4, J10) ou em tudo (A16, A18, A20), tentando fazer o melhor possível (J1), o que estivesse ao seu alcance $(\mathrm{J} 3, \mathrm{~J} 6)$. Três futuros pais (J1, J8, A21) mencionaram que se 
imaginavam um pouco atrapalhados inicialmente no cuidado do bebê: "Isso vai ser difícil, vai ser duro, porque eu sou atrapalhado para caramba, eu vou ter que aprender esses esquemas, ter habilidade para trocar fralda e tal, mas eu quero. (...) os meus sobrinhos às vezes eu trocava, embora, por exemplo, eu não soubesse que as fraldas descartáveis não absorviam as fezes, depois que foram me dizer que era só para xixi, eu achava que as fezes também, mas vai indo, vai ser uma atrapalhação, mas eu aprendo" (A21). Dois futuros pais $(\mathrm{J} 5, \mathrm{~A} 20)$ responderam ainda não saber como seria cuidar do bebê: "Não sei te dizer assim, não sei como é que vai ser. Não tenho nem idéia de como é que vai ser isto aí. Eu tenho idéia do que eu tenho que fazer, mas eu não tenho idéia de como vai ser. E nem de como fazer também (...) Eu tenho que aprender a ser pai ainda." (A20).

Contudo, vários participantes referiram-se a tarefas específicas que poderiam desempenhar, como passear (J6, J8, J9, J10, J12, A16, A19, A21, A22), trocar fraldas (J2, J3, J6, J8, J10, J12, A15, A17, A22), jogar futebol (J5, J6, J9, J10, J11, A14, A17, A19, A21), dar banho (J3, J7, J8, J9, A17, A22), alimentar (J2, J4, J6, J7, J8, J10, A15, A22), fazer dormir (J10, J12, A22), embalar (J2, A15), cuidar (J7, J12), dar colo (A13, A17), acordar à noite para cuidar (J7) e conversar (A16): "Ah, em tudo, desde trocar fralda, dar banho, 'vai lá e esquenta a papinha', dar comida para ela, tudo, tudo. Bah, eu acho que tudo, menos trocar fralda, porque eu tenho... não posso com cocô. Não sei, tentar ajudar ela nas coisas, não sei se vou conseguir também" (A20); "Eu acho que [ela] vai [me pedir ajuda], tanto que eu, eu também quero dar bastante ajuda, não quero deixar tudo para ela. Ah, [vou] cuidar dela, dar banho, trocar as fraldas, quando ela estiver chorando de noite, a C. dar de mamar e ela estiver com muito sono, eu posso ficar um pouquinho com ela" (J7).

Já em relação ao que fariam naqueles momentos difíceis, por exemplo, quando o bebê não quisesse mamar ou dormir, ou chorasse, alguns futuros pais citaram soluções baseadas em seus próprios recursos, como embalar (J1, A13), fazer dormir (J7), acalmar (J7, A21, A23), oferecer alimentos diferentes (J8, J9), conversar (A13), passear (A13), dar atenção (A13), fazer carinho (A13) e ser paciente (J10, A21). Outros participantes citaram soluções, baseadas em uma busca de auxílio/recursos externos, como a companheira, médicos, familiares e amigos (J1, A13, A18): "[quando ela chorar] Fazer carinho, pegar no colo, conversar com ela, levar para a rua (...) [quando ela não dormir] Eu acordo ela de manhã bem cedo no outro dia e deixo ela dormir pouco durante o dia, e de noite ela vai querer dormir, acostumar ela assim. Quando ela não quiser dormir, tem que dar atenção. A princípio tem que dar atenção para ela, até ela se cansar e dormir" (A13); "Pegar no colo, embalar um pouquinho para ver se acalma. Se não der, tocar para a mãe, e a mãe embala um pouco até acalmar" (J1).

Contudo, constatou-se entre vários futuros pais um desconhecimento quanto ao que fazer nesses momentos difíceis (J3, J4, J5, J6, J11, J12, A16, A18, A23), por pensarem que ficarão preocupados (J6, J11, A16) e não terem certeza de que conseguirão acalmar o bebê (A16): "Ah, não sei. A princípio vai ser no desespero, até porque é o primeiro filho" (J11); "Nesses termos de choro aí já não sei se eu vou conseguir, não sei o que eu vou fazer" (A16).
De forma geral, os depoimentos dos participantes indicaram uma vontade de participar nos cuidados do bebê, apesar de não estarem muito seguros quanto a um desempenho bem-sucedido nestas tarefas. Resultados semelhantes também foram encontrados entre pais adolescentes (Allen \& Doherty, 1996; Redmond, 1985; Westney \& cols., 1986) e entre pais adultos (Anderson, 1996; Ramires, 1997; Piccinini \& cols. 2004). Esta tendência dos futuros pais parece refletir um maior compromisso com a igualdade presente nos casais de hoje, em virtude de modificações na definição do papel paterno e materno (Cabrera, Tamis-LeMonda, Bradley, Hofferth \& Lamb, 2000; Heilborn, 1995; Ramires, 1997; Silveira, 1998; Szejer \& Stewart, 1997). No entanto, isso não significa que os pais realmente apoiarão suas companheiras após o nascimento do bebê, conforme salientado por Lewis e Dessen (1999), até mesmo pela existência de uma estrutura social que ainda domina e favorece a divisão tradicional de tarefas entre pais e mães, no caso, trabalho versus cuidado dos filhos, respectivamente.

Além disso, o apoio que será fornecido para a companheira após o nascimento do bebê parece ser uma continuação do apoio já oferecido durante a gestação. Estes achados concordam com o que referem Westney, Cole e Munford (1988), de que, quanto mais conhecimentos os futuros pais possuem sobre gravidez, cuidado pré-natal, parto e cuidado infantil, maior a probabilidade de apresentarem comportamentos de apoio à gestante e ao futuro bebê, justamente o que se apresentou entre os participantes do estudo. Stern (1997) também comenta que o futuro pai poderá ajudar a companheira como decorrência de representações de cuidado desenvolvidas ao longo de sua história, dependentes de suas relações familiares e características individuais, bem como de diretrizes culturais.

Considerando-se todos os depoimentos dos participantes, percebe-se ainda que tanto adolescentes quanto adultos imaginaram utilizar recursos próprios ou externos nas situações difíceis junto ao bebê. Assim, não parece haver relação entre a experiência prévia com bebês e a forma de lidar com situações difíceis, até porque muitos não necessariamente já teriam enfrentado tais situações.

Examinando-se os depoimentos dos futuros pais por grupos, constata-se uma diferença entre adolescentes e adultos quanto ao que fariam para ajudar a companheira. Enquanto os adolescentes tenderam a ser pouco específicos quanto ao apoio oferecido, referindo que fariam tudo o que pudessem, os adultos citaram mais atividades específicas, como dar banho e trocar fralda. Nesse sentido, poderia se pensar na onipotência do adolescente (Blos, 1962/1994, 1979/1996; Osório, 1989; Outeiral, 1994), em seu pensamento mágico, que o faz crer que poderá ajudar em tudo o que for preciso/possível. Ao mesmo tempo, poderia se pensar na falta de consciência do adolescente em relação às exigências de um bebê e às suas capacidades pessoais para atendê-las (Cochran, 1997). Contraditoriamente, os jovens também tenderam a imaginar a experiência com o próprio filho como sendo diferente daquela com outras crianças, o que poderia relacionar-se à responsabilidade que mencionaram em seu futuro papel. Assim, poderiam se sentir mais responsáveis por cuidarem de seu filho do que se sentiam antes, quando não precisavam se preocupar com questões práticas como o sustento da criança. 
Entre os grupos, constatou-se também uma tendência dos adolescentes de se imaginarem mais que os adultos desempenhando tarefas de cuidado do bebê. Este achado pode estar relacionado ao modelo paterno que influencia estes jovens, menos tradicional e mais envolvido, ou ao fato de os jovens recriarem o modelo de ausência recebido dos próprios pais. Dallas e Chen (1998) também encontraram, como no presente estudo, que adolescentes consideravam muitas tarefas como responsabilidade paterna (por exemplo, acalmar o choro, alimentar, trocar fraldas). Por outro lado, este achado contraria o que apontam Teti e Lamb (1986), uma vez que, para estes autores, os adolescentes poderiam evitar comportamentos de cuidado considerados femininos, em função de estarem consolidando sua identidade sexual.

Uma outra diferença evidenciada entre os grupos relacionou-se às expectativas quanto ao que fariam em situações difíceis: enquanto alguns adolescentes mencionaram a utilização de seus próprios recursos para lidar com o bebê, outros referiram não saber o que fazer, tendendo a solicitar auxílio da companheira. Já entre os adultos sobressaiu a expectativa de utilizar os próprios recursos, com a solicitação da companheira somente se não conseguissem solucionar a situação. Dessa forma, a postura dos adultos pareceu mais madura, com a crença no seu desempenho bem-sucedido e uma concepção de casal em que cada membro complementa o outro quando necessário. Já os adolescentes mostraram tanto uma certa onipotência, no sentido de solucionarem sozinhos as situações difíceis, baseados em suas experiências, quanto uma certa impotência, por acharem que apenas a companheira saberia o que fazer nestes momentos.

\section{Mudanças pessoais}

A última categoria tratou das expectativas e sentimentos dos futuros pais quanto às mudanças pessoais decorrentes do nascimento do filho. Foram identificadas como subcategorias: maior responsabilidade, redução da liberdade, desconhecimento em relação às mudanças pessoais, mudanças na forma de pensar, na organização da casa, maior atenção para o bebê e aumento da família.

Alguns futuros pais mencionaram expectativas de algumas mudanças pessoais após o nascimento do bebê, como o aumento da responsabilidade (J1, J2, J5, J8, A22) e a redução da liberdade (J1, J4, A17, A18, A23): "Responsabilidade eu acho. A responsabilidade aumenta, agora não tem mais festinha, não tem mais. Só quando ele estiver maiorzinho de repente. Mas vai mudar a responsabilidade, tem que aumentar" (J1); "A gente sempre saía, fazia festa, ficava até tarde na rua. A gente vai ter que se reorganizar, eu acho, essas saídas, e no resto eu acho que não, de resto tudo se encai$x a$ " (A18). Também citaram mudanças na forma de pensar e na organização da casa, uma maior atenção para o bebê e o aumento da família (J9, A19, A13): "Ah, não vai mudar muito, nós vamos fazer as mesmas coisas que nós fazíamos antes, mas com a atenção no nenê." (J9); "Olha, bem dizer vai ser o mesmo, a única coisa que vai mudar é que vai ter mais um integrante nessa família, que será amado, vai ser uma alegria para nós, que uma criança todo dia ela descobre alguma coisa, é um passo novo, sabe, nós vamos ter que passar por muita coisa, então vai ser muito legal." (A19);
"A princípio vai mudar muita coisa, vai ter um espaço que é nosso, nossa casa ali, vai mudar muita coisa até dentro de casa, o jeito de pensar, vai mudar muita coisa, vai mudar muito." (A13)

Contudo, de modo geral, os futuros pais foram vagos em suas respostas, referindo que suas vidas mudariam desde pouco (J2, J4, J9, A19, A20, A21) a muito (J3, J5, J8, J12, A13, A15, A16, A22) após a chegada do bebê. Alguns pais, mesmo comentando sobre o tema, referiram não terem uma idéia muito clara sobre o assunto (J2, J3, J5, J6, J11, J12, A19, A21): "Vai mudar muito. Ah, não sei onde que vai ser as maiores mudanças, mas vai mudar. Não sei, acho que já está mudando." (J5).

Quando questionados sobre como reagiriam às mudanças decorrentes do nascimento do bebê, vários futuros pais relataram uma reação positiva e compreensiva, até por já estarem preparados para isso (J1, J3, J5, A18, A20, A21, A22), ou ainda um desconhecimento de sua reação (J11, J12): "Sabe, eu até nem me preocupo com isso, é que eu já me acho, eu acho que já estava tão na hora de ser pai que eu acho que eu já estou me preparando a tempo assim, até sem me preocupar em pensar muito, eu já estou preparado a tempo e nem penso que vai afetar assim, talvez eu estou me iludindo, que ele vá passar as noites chorando, que eu não vou conseguir trabalhar direito, mas eu, os meus colegas às vezes comentam que têm filho, que vai mudar, mas eu não, realmente eu não me preocupo com isso. Ah, se ocorrer mudanças tranqüilo, não tem problema, não tem problema." (A21)

De modo geral, percebeu-se que tanto adolescentes quanto adultos possuíam uma idéia vaga das possíveis modificações pessoais decorrentes do nascimento de seu filho, não conseguindo expressar claramente em que aspectos estas ocorreriam, muitas vezes acreditando que não seriam tão radicais quanto comumente se fala. O que apareceu foi uma incerteza quanto a si mesmos no futuro, uma dificuldade de imaginar as modificações impostas pela nova vida, que poderia refletir uma dificuldade de pensar além da experiência atual da gravidez e/ou até mesmo o desconhecimento da situação, por serem todos futuros pais. Além disso, como comenta Stern (1997), como as representações dos pais seriam menos modificadas que as das mães durante a gravidez, isto poderia lhes dificultar pensar nas mudanças decorrentes da chegada do bebê.

Já para aqueles que conseguiram vislumbrar de forma mais concreta as modificações pessoais decorrentes da chegada do bebê, a maior responsabilidade e a conseqüente redução da liberdade foram citadas por participantes de ambos os grupos. Estas mesmas restrições impostas pela paternidade foram encontradas por diversos autores (por ex., Belsky \& Miller, 1986; Nunes, 1998; Bustamante, 2005).

No entanto, comparando-se os grupos, sobressaiu-se uma tendência dos adolescentes a citarem o aumento de responsabilidade, enquanto que os adultos enfatizaram mais a redução da liberdade. Isto talvez se deva ao fato dos adultos já terem assumido mais responsabilidades em função de sua idade e estado civil. Além disso, as mudanças pessoais esperadas parecem ser uma continuação daquelas mencionadas como decorrentes da gravidez.

Constatou-se ainda, comparando os relatos dos dois grupos, que os futuros pais adultos pareceram se sentir mais 
preparados para aceitar as mudanças do que os adolescentes, que pareceram nem conseguir pensar sobre o assunto, talvez pela limitação cognitiva que os impede de vislumbrar um futuro mais distante (McKinney, Fitzgerald \& Strommen, 1977; Montmayor, 1986; Piaget \& Inhelder, 1976), ou pelo choque de uma paternidade não planejada (Trindade \& Bruns, 1999).

\section{Considerações Finais}

O presente estudo buscou comparar futuros pais adolescentes e adultos em suas expectativas e sentimentos em relação à paternidade, no intuito de contribuir para um maior entendimento do fenômeno da paternidade adolescente. A expectativa inicial do estudo, de grandes diferenças entre os grupos em relação às expectativas e sentimentos quanto à paternidade, foi apenas parcialmente corroborada, pois foram encontradas várias semelhanças nos relatos de futuros pais adolescentes e adultos, como descrito anteriormente. Dessa forma, a idade não pareceu ser um fator determinante para a vivência da paternidade, pelo menos entre os pais do presente estudo. Vários deles apresentaram preocupações e sentimentos comuns entre futuros pais em geral, o que reforça a idéia de que a paternidade na adolescência não pode mais ser considerada como fato irrelevante, continuando esquecido e desconhecido (Fonseca, 1997, 1998). Ao contrário, estes futuros pais necessitam ser conhecidos e terem atendidas as suas necessidades, para que possam desempenhar de forma mais efetiva seu novo papel em idade precoce.

\section{Referências}

Allen, W. D. \& Doherty, W. J. (1996). The responsibilities of fatherhood as perceived by African American teenage fathers. Families in Society: The Journal of Contemporary Human Services, 77(3), 142-155.

Anderson, A. M. (1996). Factors influencing the father-infant relationship. Journal of Family Nursing, 2(3), 306-324.

Aquino, E. M. L.; Heilborn, M. L.; Knauth, D.; Bozon, M.; Almeida, M. da C.; Araújo, J. \& Menezes, G. (2003). Adolescência e reprodução no Brasil: A heterogeneidade dos perfis sociais. Cadernos de Saúde Pública, 19(2), 377-388.

Bardin, L. (1977). Análise de conteúdo. Lisboa: Edições70.

Belsky, J. \& Miller, B. C. (1986). Adolescent fatherhood in the context of the transition to parenthood. Em A. B. Elster \& M. E. Lamb (Orgs.), Adolescent fatherhood (pp. 107-121). Hillsdale: Lawrence Erlbaum.

Blos, P. (1994). Adolescência: Uma interpretação psicanalítica. (W. Dutra, Trad.) São Paulo: Martins Fontes. (Trabalho original publicado em 1962)

Blos, P. (1996). Transição adolescente: Questões desenvolvimentais. (M. R. Hofmeister, Trad.) Porto Alegre: Artes Médicas. (Trabalho original publicado em 1979)

Brazelton, T. B. \& Cramer, B. G. (1992). As primeiras relações. (M. B. Cipolla, Trad.) São Paulo: Martins Fontes. (Trabalho original publicado em 1990).

Bustamante, V. (2005). Ser pai no subúrbio ferroviário de Salvador: Um estudo de caso com homens de camadas populares. Psicologia em Estudo, 10(03), 393-402.
Cabral, C. S. (2003). Contracepção e gravidez na adolescência na perspectiva de jovens pais de uma comunidade favelada do Rio de Janeiro. Cadernos de Saúde Pública, 19(2), 283-292.

Cabrera, N. J.; Tamis-LeMonda, C. S.; Bradley, R. H.; Hofferth, S. \& Lamb, M. E. (2000). Fatherhood in the twenty-first century. Child Development, 71(1), 127-136.

Carvalho, M. L. M. de. (2003). Participação dos pais no nascimento em maternidade pública: Dificuldades institucionais e motivações dos casais. Cadernos de Saúde Pública, 19(2), 389-398.

Castoldi, L. (2002). A construção da paternidade desde a gestação até o primeiro ano do bebê. Tese de Doutorado, Universidade Federal do Rio Grande do Sul, Porto Alegre.

Christmon, K. (1990). Parental responsibility of African American unwed adolescent fathers. Adolescence, XXV(99), 645-653.

Cochran, D. L. (1997). African american fathers: A decade review of the literature. Families in Society: The Journal of Contemporary Human Services, 78(4), 340-351.

Costa, R. G. (2002). Reprodução e gênero: Paternidades, masculinidades e teorias da concepção. Revista Estudos Feministas, 10(2), 339-356.

Costa, M.C. O.; Lima, I. C.; Martins Júnior, D. F.; Santos, C. A. S. T.; Araújo, F. P. O. \& Assis, D. R. (2005). Gravidez na adolescência e co-responsabilidade paterna: Trajetória sócio-demográfica e atitudes com a gestação e a criança. Ciência e Saúde Coletiva, 10(3), 719-727.

Dallas, C. M. \& Chen, S. C. (1998). Experiences of African American adolescent fathers. Western Journal of Nursing Research, 20(2), 210-222.

Daly, K. (1993). Reshaping fatherhood: Finding the models. Journal of Family Issues, 14(4), 510-530.

Dellmann-Jenkins, M.; Sattler, S. H. \& Richardson, R. A. (1993). Adolescent parenting: A positive, intergenerational approach. Families in Society: The Journal of Contemporary Human Services, 74(10), 590-601.

Elster, A. B. \& Hendricks, L. (1986). Stresses and coping strategies of adolescent fathers. Em A. B. Elster \& M. E. Lamb (Orgs.), Adolescent fatherhood (pp. 55-65). Hillsdale: Lawrence Erlbaum.

Fonseca, J. L. (1997). Paternidade adolescente: Uma proposta de intervenção. Dissertação de Mestrado, Pontifícia Universidade Católica de São Paulo, São Paulo.

Fonseca, J. L. C. L. (1998). Paternidade adolescente: Da investigação à intervenção. Em M. Arilha, S. G. U. Ridenti \& B. Medrado (Orgs.), Homens e masculinidades: Outras palavras (pp. 185214). São Paulo: Editora34.

Grupo de Interação Social, Desenvolvimento de Psicopatologia - GIDEP (1998a). Termo de consentimento informado. Universidade Federal do Rio Grande do Sul, Porto Alegre.

Grupo de Interação Social, Desenvolvimento de Psicopatologia - GIDEP (1998b). Entrevista de contato inicial. Universidade Federal do Rio Grande do Sul, Porto Alegre.

Grupo de Interação Social, Desenvolvimento de Psicopatologia - GIDEP (1998c). Entrevista de dados demográficos do casal. Universidade Federal do Rio Grande do Sul, Porto Alegre.

Grupo de Interação Social, Desenvolvimento de Psicopatologia - GIDEP (1998d). Entrevista sobre a gestação e as expectativas do futuro pai. Universidade Federal do Rio Grande do Sul, Porto Alegre. 
Gomes, A. J. S. \& Resende, V. R. (2004). O pai presente: O desvelar da paternidade em uma família contemporânea. Psicologia, Teoria e Pesquisa, 20(2), 119-125.

Heilborn, M. L. (1995). O que faz um casal, casal? Conjugalidade, igualitarismo e identidade sexual em camadas médias urbanas. Em I. Ribeiro \& A. C. T. Ribeiro (Orgs.), Família em processos contemporâneos: Inovações culturais na sociedade brasileira (pp. 91-106), Coleção Seminários Especiais, Centro João XXIII(10). São Paulo: Loyola.

Heilborn, M. L.; Salem, T.; Rohden, F.; Brandão, E.; Knauth, D.; Victora, C.; Aquino, E.; McCallum, C. \& Bozon, M. (2002). Aproximações sócio-antropológicas sobre a gravidez na adolescência. Horizontes Antropológicos, 8(17), 13-45.

Hendricks, L. E. (1980). Unwed adolescent fathers: Problems they face and their sources of social support. Adolescence, $X V(60)$, 861-869.

Hendricks, L. E. (1988). Outreach with teenage fathers: A preliminary report on three ethnic groups. Adolescence, XXIII(91), 711-720.

Hendricks, L. E. \& Montgomery, T. (1983). A limited population of unmarried adolescent fathers: A preliminary report of their views on fatherhood and the relationship with the mothers of their children. Adolescence, XVIII(69), 201-210.

Hennigen, I. \& Guareschi, N. M. de F. (2002). A paternidade na contemporaneidade: Um estudo de mídia sob a perspectiva dos Estudos Culturais. Psicologia e Sociedade, 14(01), 44-68.

Krob, A. R. (1999). A transição para a paternidade e a interação pai-bebê. Dissertação de Mestrado, Universidade Federal do Rio Grande do Sul, Porto Alegre.

Lamb, M. E. \& Elster, A. B. (1986). Parental behavior of adolescent mothers and fathers. Em A. B. Elster \& M. E. Lamb (Orgs.), Adolescent fatherhood (pp. 88-106). Hillsdale, New Jersey: Lawrence Erlbaum.

Laville, C. \& Dionne, J. (1999). A construção do saber: Manual de metodologia de pesquisa em Ciências Humanas. (H. Monteiro \& F. Settineri, Trads.). Porto Alegre: Artes Médicas. (Trabalho original publicado em 1997)

Levandowski, D. C. (2001a). Paternidade na adolescência: Breve revisão da literatura internacional. Estudos de Psicologia (Natal), 6(2),195-209.

Levandowski, D. C. (2001b). Paternidade na adolescência: Expectativas, sentimentos e a interação com o bebê. Dissertação de Mestrado, Universidade Federal do Rio Grande do Sul, Porto Alegre.

Levandowski, D. C. \& Piccinini, C. A. (2002). A interação pai-bebê entre pais adolescentes e adultos. Psicologia Reflexão e Crítica, 15(2), 413-424.

Levandowski, D. C. \& Piccinini, C. A. (2004). Paternidade na adolescência: Aspectos teóricos e empíricos. Revista Brasileira de Crescimento e Desenvolvimento Humano, 14(1), 51-67.

Lewis, C. \& Dessen, M. A. (1999). O pai no contexto familiar. Psicologia: Teoria e Pesquisa, 15(1), 09 - 16.

Marsiglio, W. \& Cohan, M. (1997). Young fathers and child development. Em M. E. Lamb (Org.), The role of the father in child development (pp. 227-244, 3ed.) New York: John Wiley $\&$ Sons.

Martini, T. D. (1999). A transição para a paternidade: Expectativas, sentimentos e síndrome de couvade dos futuros pais ao longo da gestação. Dissertação de Mestrado, Universidade Federal do Rio Grande do Sul, Porto Alegre.
McKinney, J. P.; Fitzgerald, H. E. \& Strommen, E. A. (1977). Developmental psychology: The adolescent and young adult. Homewood: Dorsey Press.

Montmayor, R. (1986). Boys as Fathers: Coping with the dilemmas of adolescence. Em A. B. Elster \& M. E. Lamb (Orgs.), Adolescent fatherhood (pp. 01-18). Hillsdale: Lawrence Erlbaum.

Nachmias, C. \& Nachmias, D. (1996). Research methods in the social sciences. London: Arnolds.

Nunes, C. E. G. (1998). Adolescência e paternidade: Um duelo de papéis sociais. Psico, 29(1), 125-138.

Osório, L. C. (1989). Adolescência hoje. (2ed.) Porto Alegre: Artes Médicas.

Outeiral, J. O. (1994). Adolescer: Estudos sobre adolescência. Porto Alegre: Artes Médicas.

Parke, R. (1996). Fatherhood. London: Harvard University Press.

Parke, R. D.; Power, T. G. \& Fisher, T. (1980). The adolescent father's impact on the mother and child. Journal of Social Issues, 36(1), 88-106.

Piaget, J. \& Inhelder, B. (1976). Da lógica da criança à lógica do adolescente: Ensaio sobre a construção das estruturas operatórias formais. (D. M. Leite, Trad.). São Paulo: Pioneira. (Trabalho original publicado em 1970)

Piccinini, C. A.; Tudge, J.; Lopes, R. S. \& Sperb, T. M. (1998). Estudo longitudinal de Porto Alegre: Da gestação à escola. Instituto de Psicologia. Projeto de Pesquisa, Porto Alegre, UFRGS.

Piccinini, C. A.; Silva, M. da R.; Gonçalves, T. R.; Lopes, R. S. \& Tudge, J. (2004). O envolvimento paterno durante a gestação. Psicologia, Reflexão e Crítica, 17(3), 303-314.

Ramires, V. R. (1997). O exercício da paternidade hoje. Rio de Janeiro: Rosa dos Tempos.

Redmond, M. A. (1985). Attitudes of adolescent males toward pregnancy and fatherhood. Family Relations Journal of Apply Family and Child Studies, 34(3), 337-342.

Rhein, L. M., Ginsburg, K. R., Schwarz, D. F., Pinto-Martin, J. A., Zhao, H., Morgan, A. P. \& Slap, G. B. (1997). Teen father participation in child rearing: family perspectives. Journal of Adolescent Health, 21(4), 244-252.

Robinson, B. E. (1988). Teenage pregnancy from the father's perspective. American Journal of Orthopsychiatry, 58(1), 46-51

Sherwen, L. N. (1986). Third trimester fantasies of first-time expectant fathers. Maternal Child Nursing Journal, 15(3), 153-170.

Silva, M. R. da (2003). Sentimentos sobre a paternidade e envolvimento de pais que residem e pais que não residem com seus filhos. Dissertação de Mestrado, Universidade Federal do Rio Grande do Sul, Porto Alegre.

Silveira, P. (1998). Exercício da paternidade. Porto Alegre: Artes Médicas.

Siqueira, M. J. T.; Mendes, D.; Finkler, I.; Guedes, T. \& Gonçalves, M. D. S. (2002). Profissionais e usuárias(os) adolescentes de quatro programas públicos de atendimento pré-natal da região da grande Florianópolis: Onde está o pai? Estudos de Psicologia (Natal), 7(1), 65-72.

Stern, D. N. (1997). A constelação da maternidade: O panorama da psicoterapia pais/bebê. (M. A. V. Veronese, Trad.). Porto Alegre: Artes Médicas. (Trabalho original publicado em 1995) 
Szejer, M. \& Stewart, R. (1997). Nove meses na vida da mulher: Uma abordagem psicanalítica da gravidez e do nascimento. (M. N. B. Benetti, Trad.). São Paulo: Casa do Psicólogo. (Trabalho original publicado em 1997)

Teti, D. M. \& Lamb, M. E. (1986). Sex-role learning and adolescent fatherhood. Em A. B. Elster \& M. E. Lamb (Orgs.), Adolescent fatherhood (pp. 19-30). Hillsdale, New Jersey: Lawrence Erlbaum.

Trindade, Z. A. (1993). As representações sociais e o cotidiano: A questão da maternidade e da paternidade. Psicologia: Teoria e Pesquisa, 9(3), 535-546.

Trindade, E. \& Bruns, M. A. de T. (1999). Adolescentes e paternidade: Um enfoque fenomenológico. Ribeirão Preto: Holos.

Trindade, Z. A. \& Menandro, M. C. S. (2002). Pais adolescentes: vivência e significação. Estudos de Psicologia (Natal), 7(1), 15-23.
Westney, O. E.; Cole, O. J. \& Munford, T. L. (1986). Adolescent unwed prospective fathers: Readiness for fatherhood and behaviors toward the mother and the expected infant. Adolescence, XXI(84), 901-911.

Westney, O. E.; Cole, O. J. \& Munford, T. L. (1988). The effects of prenatal education intervention on unwed prospective adolescent fathers. Journal of Adolescent Health Care, 9(3), 214-218.

Young, M. (1988). Parenting during mid-adolescence: A review of developmental theories and parenting behaviors. Maternal Child Nursing Journal, 17(1), 01-12

Recebido em 12.01.2005

Primeira decisão editorial em 05.12.2005

Versão final em 20.02.2006

Aceito em 12.04.2006

\section{CONGRESSO NACIONAL DA ASSOCIAÇÃO BRASILEIRA DE RORSCHACH E MÉTODOS PROJETIVOS ASBRO 2006}

\section{Método Projetivos: Investigações Psicológicas, Cultura e Subjetividade}

Data: 10 a 14 de Junho de 2006

Local: Universidade de Brasília e Universidade Católica de

Brasília - Brasília/DF

\section{Organização}

Universidade de Brasília

Universidade Católica de Brasília

\section{Informações e inscrições}

http://www.ucb.br/psicologia/unb/congressororschach/ http://www.finatec.com.br/evento/asbro/inscrição.asp 